\title{
Assessing Operating Team Practices of Surgical Safety Measures Applied to Intraoperative Orthopedic Patients
}

\author{
Amal Samir Ahmed, Assistant Professor \\ Medical Surgical Nursing, Faculty of Nursing, Alexandria University, Egypt
}

\begin{abstract}
Promoting patient safety is the fundamental role of health care, yet care-related adverse events can be disastrous for patients, families and health settings. Surgical patient safety is still challenge in operation, in spite of the development of the Universal Protocol. Objective: Assess orthopedic patients' safety in the operating room. Setting: The operating rooms at ElHadara University Hospital in Alexandria, Egypt. Subjects: 200 intra-operative patients undergoing orthopedic surgery and all surgeons $(N=10)$, anesthetists $(N=4)$ and nurses (N=28). Tool: Surgical Safety Checklist administered to assess operating team practices comprises a pre-operative verification process, sign in, time out, and sign out. Results: The findings revealed that the highest performance items of the operating team were related to patient ID, surgical site marked, patient consent, images, supplies, antibiotics given, and sterile instruments check; the worst performance items were assessing patient for risk of excessive blood loss and difficulty of airway or aspiration $162 \%$ and 57\%, respectively).Reviewing the key concerns for recovery was undertaken for only $62 \%$ of patients. The results also imply that the differences between parts of surgical safety and patients' age, as well as types of surgeries, were statistically significant. Conclusion: The high mean score of surgical safety applied by operating team was related to phase I (preoperative verification) and phase IV (sign out). Recommendations: The findings highlight the need for using Surgical Safety Checklist in the operating room to maintain safety culture and prevent complications.
\end{abstract}

Kevwords: Operating team; Surgical safety; Orthopedic patients.

\section{Introduction}

Orthopedic surgery is a highly specialized are with the greatest technical complexity in terms of equipment demands and staff training, therefore there is an inherently increased contextual probability for errors to occur ${ }^{(1)}$. Promoting patient safety is a major priority for surgeons and hospitals, since sentinel events can be catastrophic for patients, their families, health professionals and health settings. Recent alertness to patient safety stems from several high level of medical errors and several institutes of medicine reports which quantified the problem, created standardized definitions, and charged the healthcare community to develop improved hospital operating systems ${ }^{(2)}$. The promotion of patient safety has been further advanced by the recent malpractice events in operation and the demonstrated vulnerability and destructive hospitals face after public exposure of a sentinel event. Both national and international literature show that a large proportion of in-hospital preventable adverse events can be attributed to surgical systems, and more than half of all reported adverse events are related to surgical procedures ${ }^{(3,4)}$.

Compared with other hospital settings, errors in the operating room can be particularly disastrous, and in some cases can result in high-level consequences for a surgeon and an institution. Wrongsite/wrong-procedure surgeries, retained sponges, unchecked blood transfusions, mismatched organ transplants and overlooked allergies are all examples of potentially disastrous events that can 
generally be avoided by improved communication and safer hospital systems $^{(2,5,6)}$.

The Safe Surgery Saves Lives initiative was established by the World Alliance for Patient Safety as part of the World Health Organization's efforts to reduce the number of surgical mortality across the world. The aim of this initiative is to address important safety issues, including insufficient anesthetic safety practices, preventable surgical infection and poor communication among team members. These issues have proved to be common, deadly and preventable problems in all countries and settings. To assist operating teams in decreasing the number of these events, the Alliance in consultation with surgeons, anesthesiologists, nurses, patient safety experts and patients around the world has identified a set of safety checklists that could be practiced in any operating theater ${ }^{(5,7,8)}$.

Nurses are considered to be the most vital input in any health care system, and they have a major effect on quality of health care as an output. Moreover, nurses are key to safety improvement in different aspects ${ }^{(9)}$.

Throughout surgery, nursing duties include providing for the safety and wellbeing of the patient, coordinating the operating room personnel, and performing scrub and circulating activities. In the role of patient advocate, intraoperative nurses monitor factors that can cause injury, such as patient position, equipment malfunction and environmental hazards, and they protect patients' dignity and interests while they are anesthetized. In addition, they maintaining surgical standards of care, identifying existing patient risk factors and helping to modify complicating factors to decrease operative risk $^{(10)}$.

Direct observation and assessment of surgical teams greatly promotes our understanding of the key determinants of high practice in operation and good clinical outcomes. Patient risk factors and surgical, anesthetic and nursing skill will always be essential, but more masterful factors may be of particular importance when designed for very high levels of practice. Put simply, good surgical skills coupled with basic team performance and basic equipment may enable a surgeon to achieve a $90 \%$ success rate in a high-risk operation; however, refinements in surgical skill may be a relatively small element in the drive to decrease mortality from $10 \%$ to $1 \%{ }^{(11)}$.

The improvement of systemic factors, such as optimizing the surgical environment, attention to ergonomics and equipment design, understanding the subtleties of decision making in a dynamic environment, improving communication and team performance may be more important than surgical/medical skill when aiming for truly high performance ${ }^{(12)}$. However, despite the introduction of the Universal Protocol, surgical patient safety remains a daily challenge in the operating theater. Therefore, this study was carried out to assess intra-operative patient's safety in the more specialized area of orthopedic surgery.

\section{Aim of the Study}

The aim of the study was to assess operating team practices of surgical safety measures applied to intraoperative orthopedic patients.

\section{Research Question:}

Does the operating team follow surgical safety measures in orthopedic surgery?

\section{Materials and Method}

\section{Materials}


Design: A descriptive research design was utilized for this study.

Setting: The operating rooms at El Hadara University Hospital in Alexandria, Egypt.

Subjects: The subjects of this study included all surgeons $(\mathrm{N}=10)$, anesthetists $(\mathrm{N}=4)$ and nurses $(\mathrm{N}=28)$ working in the setting, and a convenience sample of 200 intra-operative patients undergoing orthopedic surgery there. Epi Infro program was used to estimate the required patient sample size.

Tool: The following tool was used:

\section{Surgical Safety Checklist}

The tool was adopted from World Health Organization Surgical Safety Checklist $(2009)^{(5)}$ and the Pennsylvania Patient Safety Authority $(2011)^{(13)}$. This tool was used to assess operating team practices of surgical safety measures applied to intraoperative orthopedic patients. It consists of four parts related to four intraoperative phases, as described below.

Part I: Pre-operative verification phase includes items to assure that the correct operation site was written on the operating schedule, the patient history record as well as the patient consent sheet. It verifies operative site marking and patient identity, confirming that all documents and studies, required blood products, implant devices and special equipment are available before starting the procedure, and assures that all sterile equipment and supplies are prepared.

Part II: Sign in phase - performed before induction of anesthesia; this includes assessment for allergies, difficult airways and expected blood loss, and checking the medication and anesthesia machine.

Part III: Time out phase - done after induction of anesthesia and before surgical incision, this is used by the operating team to verbally verify the patient's name, operation and position, the use of antibiotic prophylaxis within previous 60 minutes before the incision, the use of prophylactic anticoagulant, the presence of the correct imaging and equipment sterility.

Part IV: Sign out phase - occurs after closure of the wound but prior to transferring the patient to the recovery room, and used to confirm the operation done and the count of sponge and instruments, and adding to plans for recovery management. Each item in the checklist was classified as yes, no or not applicable. Patient characteristics such as name, age, gender, medical diagnosis and surgery were attached in the tool.

\section{Method}

- Permission to collect data for the study was obtained from the Hospital manager and the Head of Operating Room. In addition, the study's aim was cleared to the operating team (surgeons, anesthetists and nurses) and surgical patients.

- The content validity of the tool was revised by a five experts in medical surgical nursing to assess clarity and validity of the tool. A pilot study was done on 20intraoperative patients to determine its clarity and feasibility. The tool's reliability was tested using Cronbach's alpha coefficient test (0.75), indicating that it was reliable. Operating team practices were observed by the researcher throughout the four intraoperative phases.

- During phase 1 (preoperative verification) the operating team were observed to ensure that they verify that the patient identity and mark the operative site. During this phase it was also important to confirm the availability of all documents and studies before starting the procedures.

- During phase II (sign in), before the administration of anesthesia, the operating team was observed to confirm that patient was connected with pulse oximeter and to check of 
anesthesia machine. Also, the researcher observed whether surgeons verbally reviewed with anesthetists the risk of hemorrhadge, difficult airway and allergic reaction.

- During phase III (time out), before the skin incision, the researcher observed the operating team to assess whether all the team introduced themselves and their roles by name and that the team verbally confirmed the correct patient, operation and site. Also, it was observed that they assured the giving of antibiotics within an hour prior to the operation and display of necessary imaging, as appropriate.

- During phase IV (sign out), after the closure of the wound but before transferring the patient to the recovery room, the researcher observed if the operating team verbally verified the name of procedure, the counts of instrument and supplies and the label of any specimens obtained, as well as checking any equipment malfunctions of equipment that need to be recorded. Lastly, the researcher assessed if the operating team reviewed the key points of postoperative management plan before transferring the patient to the recovery room.

\section{Ethical considerations:}

The participants were informed about the purpose of the study. Written consent to take part in the study was obtained from the operating room staff and the patients before beginning data collection. Also, Participants' privacy and confidentiality were ensured.

\section{Statistical Analysis}

Data were analyzed using SPSS version 20. Descriptive and inferential statistics were performed on the items of the checklist. Participant characteristics were described by using frequencies, means and standard deviations. The non-parametric method of statistical analysis was used, since the variables did not follow the normal distribution. In addition, KruskallWallis test was used instead of (ANOVA).

\section{Results}

Table (1) shows that more than half of patients $(56.5 \%)$ were male, and a mean age of patients was 35.75 years $(\mathrm{SD}=18.924)$. In addition, more than one-third of orthopedic surgeries $(38.5 \%)$ were open reduction internal fixation surgery.

Table (2) shows that during preoperative verification phase, the majority of the operating team performed most of the items or practices (91-100\%), while required blood products, special equipment and implant devices were checked by $60 \%, 70 \%$ and $71 \%$, respectively.

Table (3) shows that only $57 \%$ of the operated patients were assessed for the risk of a difficult breathing and aspiration, while the risk for greater than $500 \mathrm{ml}$ blood loss was assessed among only $62 \%$ of the patients. In addition, $69 \%$ of the patients were assessed to confirm any known allergies.

Table (4) shows that introducing all team members to each other was restricted to $2.5 \%$ of the sample. In addition, the results revealed that $59 \%, 69 \%$, and $69.5 \%$ respectively of the operated patients were checked by the operating team for any specific concerns, confirming their name and checking any special equipment.

Table (5) shows that during all 200 operated patients included in the study, (93\%) was not applicable and only $7 \%$ of the patients required specimen testing, for half of them $(3.5 \%)$, the operating team read the specimen aloud and included patients' names. Moreover, $17.5 \%$ of operated patients out of the total participants, 
equipment problems were occurred and addressed during their operations. Moreover, $100 \%$ and $99 \%$ of the operating team respectively recorded the name of the procedure and completed the instrument, sponge and needle counts. Review of key concerns for recovery and management of patients was undertaken for $62 \%$ of patients.

Table (6) illustrates the mean score and standard deviations of four parts of surgical safety practices. The findings revealed that high mean scores of surgical safety applied by the operating team were related to phase I (preoperative verification) and phase IV (sign out) (89.75 and 86.48 respectively).

Table (7) shows that the highest means were reported regarding surgical safety practices during total hip and total knee replacement surgeries. Also, significant differences were found between joint replacement surgeries and other types of orthopedic surgeries in part I and part II of the Surgical Safety practices $(\mathrm{P}=.003, .001$ respectively).

Table (8) shows that there is a positive trend in mean score to increase as age increases regarding the surgical safety practices rendered during the four parts of surgical safety. Moreover, the differences were significant $(\mathrm{P}=.005, \mathrm{P}=.002, \mathrm{P}=.026$, $\mathrm{P}=.008$ ).

\section{Discussion}

Patient safety is the essential concern of healthcare. In the operating room errors are frequent and often consequential ${ }^{(14)}$, therefore attention to the issue of patient safety is universally acknowledged as a crucial issue in the health systems of different countries. Patient safety, as one of the essential components of health care quality, means avoiding patient injury while providing health care. Reducing medical errors depends on a safe environment in the systemic and clinical fields ${ }^{(15)}$.

The WHO Surgical Safety Checklist was developed in 2009 in coordination with their Safe Surgery Saves Lives initiative to promote safety in all surgery around the world. The direct observation and evaluation of operating teams extremely reinforces our perception of the critical factors of high performance in surgery ${ }^{(16)}$. The present study results showed that preoperative verifications items related to patient identity, surgical site marked, patient consent, images, sterile equipment and supplies check were applied for the majority of patients. The interpretation could be related to staff awareness of the importance of checking the site of surgery to prevent wrong-site surgery, and the availability of instruments and supplies in the operating theater, which need just a few minutes to check. Conversely, Robinson and Muir (2009) indicated that wrong-site surgery (WSS) commonly occurred in orthopedic surgery, general surgery and neurosurgery $^{(17)}$.

In response to preventable errors, the Joint Commission and American Academy of Orthopedic Surgeons (AAOS) implemented a universal protocol that requires a pre-operative verification process, the marking of the operative site and taking a 'time out 'immediately prior to starting the procedure ${ }^{(18,19)}$. In line with this study's findings, the Committee on Patient Safety and Quality Improvement (2010) reported that effective preoperative patient assessment includes a review of medical records or imaging studies immediately before starting surgery. A briefing is important for assigning essential roles and establishing expectations ${ }^{(20)}$.

Moreover, Frederique and Kjeld (2014) indicated that there is no doubt that marking the operated side and performing a time out procedure is a good tool in preventing errors; however, errors still happen, due to an unawareness of the health care staff to the importance of prevention procedures. Continued education and promoting awareness may be of benefit in preventing these adverse events ${ }^{(21)}$. In the current study it was noticed that items checked less frequently included blood 
products required as well as implant devices available. In this context, Geraldo et al. (2013) indicated that most errors experienced in surgical theater were related to problems with equipment being incomplete or damaged after the start of procedures, related to communication failures $^{(22)}$.

Regarding operating team performance during the sign in phase, the core items of anesthetic medication, anesthesia machine, and pulse oximeter check were consistently assessed. However, there were some steps which were not always well performed including assess patient for difficulty airway or aspiration. This finding was supported by WHO Guidelines for Safe Surgery, which illustrated that the risk of aspiration should be checked as part of the airway assessment. If the patient has symptomatic active reflux or a full stomach, the anesthetist must prepare for the probability of aspiration. In addition, induction of anesthesia should start only when adequate equipment has been confirmed by the anesthetis. Moreover, WHO mentioned that, the anesthetists should assess airway equipment, breathing system, suction and emergency medications to confirm their availability and functioning ${ }^{(5)}$.

The present results also showed that the risk for more than $500 \mathrm{ml}$ blood loss was assessed by surgeons among two-thirds of studied patients. This may be related to a lack of awareness about the importance of estimating the amount of blood loss intraoperatively. In this respect, the World Health Organization revealed that surgical patients risk for hypovolemic shock is mainly caused by excessive blood loss ${ }^{(5)}$. In addition, Nissen et al. (2017) mentioned that the hazards of blood loss may not be reported to operating team by surgeons ${ }^{(23)}$.

Concerning time out phase, the findings indicated that few members of operating teams introduced themselves to each other, which could be due to their great familiarity. On the other hand, Makary et al. (2006) indicated that introduction of each person in the operating room by name and role, even if team members are familiar, is recommended for improved communication $^{(2)}$. In this regard, Rydenfalt et al. (2013) and Ragusa et al. (2015) insisted that the first part of the time out is important for facilitating communication, because this is when all the team members introduce themselves by name and role. This is not only because everybody needs to know who is doing what in the operating theatre, but also to ensure that all team members feel included and free to discuss their concerns ${ }^{(24,25)}$.

In the present study, checks for the prevention of potentially severe postoperative problems such as deep vein thrombosis(DVT) and surgical site infection were performed in the majority of patients (venous thrombolism prophylaxis, antibiotics prophylaxis). The rationale may be that the orthopedic patients are a high risk group for thrombus formation. Gans et al. (2017) revealed that the majority of general surgeons checked antibiotic prophylaxis and frequently checked DVT prophylaxis; moreover, perioperative antibiotic prophylaxis can help prevent surgical site infection ${ }^{(26)}$.

Checking the sterility of instruments was practiced by the nurses for all surgical patients, indicating their diligent compliance with infection control measures. In this respect, Labrague et al. (2012) stated that nurses play significant role in infection control, because they undertake a high proportion of the treatment and care of surgical patients ${ }^{(27)}$.

Reviewing the key concerns for recovery and management of the patients was done for nearly two-thirds of patients. The interpretation could be that the time after finishing of surgery is a busy time for operating team and each one of them focused on their duties. De Vries et al. (2010) revealed that negative events in patients who have undergone surgery form a large percentage of iatrogenic illnesses. Most surgical safety interventions have 
focused on the operating room; since more than half of all surgical errors occur outside the operating room, it is likely that a more substantial improvement in outcomes can be achieved by targeting the entire surgical pathway, particularly including recovery ${ }^{(28)}$.

Furthermore, Lingard (2004) and Melekie1 \& Getahun (2015) revealed that communication failures among operating teams are frequent, occurring in approximately $30 \%$ of procedurally relevant exchanges among team members. These failures are based on the following factors: communication is too late to be effective, key individuals are excluded, and issues are left unresolved until the point of $\operatorname{urgency}^{(29,30)}$.

The findings of this study indicated that surgical safety measures are more applied for older age patients than younger age. The interpretations could be that the elderly are at higher risk of mortality and morbidity due to co-morbidities. In this respect, Griffiths (2014) reported that in comparison with younger patients, older people undergoing elective and emergency surgery are at higher risk of adverse postoperative outcomes, due to some combination of age-related physiological decline, multiple co-morbidities, polypharmacy, cognitive dysfunction and geriatric syndromes, including frailty ${ }^{(31)}$.

The results of the study revealed that safety measures during the four phases of surgery are more highly applied for patients undergoing joint replacement surgeries than other orthopedic surgeries. One explanation for this is that the joint replacement surgeries are considered major surgeries, and the patients may be at high risk of complications, thus surgical safety measures should be strictly applied. This result supports Griffith set al. (2014), who mentioned that joint replacement is thrombogenic and ischemogenic; the surgery often takes a long time of anesthesia in operating room, usually on an elderly patient with associated comorbidities. Moreover, it is associated with significant operative blood loss in a physiologically deconditioned patient ${ }^{(31)}$.

Finally, the study findings indicated that there is still potential for improving the practice and culture of surgical patient safety activities. Staff training and designation of patient safety leadership roles is needed in increasing compliance and implementation of patient safety mechanism, such as peri-operative checklists.

\section{Conclusion}

The findings of this study concluded that the highest performance of operating team was related to patient ID, surgical site marked, patient consent, images, supplies, antibiotics, and sterile instruments check; the worst performance was related to assessing patient for risk of excessive blood loss, difficulty in airway or aspiration and reviewing the key concerns for recovery. The results also revealed that the high mean score of surgical safety applied by operating team was related to phase I (preoperative verification) and phase IV (sign out). Finally, statistically significant differences were found between phases of surgical safety and patient's age, as well as types of surgeries. The study findings indicated that the Surgical Safety Checklist is greatly needed for the operating team to safeguard patient safety. In addition, communication among the operating team is significant.

\section{Recommendations}

- In service training program should be provided to all orthopedic operating team about Surgical Safety Checklist and the importance of applying the checklist.

- A shortened version of the checklist should be introduced to promote use and effect more straightforward procedures.

- Providing the checklist in a poster, whiteboard or other more participatory format would enable all of the 
operating team to follow the checks and engage in the process.

- Patient safety culture should be integrated in the nursing curriculum in order to increase awareness of patient safety. 
Table (1): Distribution of the surgical patients according to their characteristics

\begin{tabular}{|c|c|c|}
\hline Patient characteristics & $(\mathrm{N}=200)$ & $\%$ \\
\hline $\begin{array}{l}\text { Gender } \\
\text { Male } \\
\text { Female }\end{array}$ & $\begin{array}{c}113 \\
87\end{array}$ & $\begin{array}{l}56.5 \\
43.5\end{array}$ \\
\hline $\begin{array}{l}\text { Age (years) } \\
20<30 \\
30<40 \\
40<50 \\
50<60 \\
60<70 \\
70<80 \\
\text { Mean participant age }(\mathbf{3 5 . 7 5})(\mathrm{SD}=\mathbf{1 8 . 9 2 4})\end{array}$ & $\begin{array}{c}80 \\
37 \\
25 \\
30 \\
21 \\
7\end{array}$ & $\begin{array}{c}40 \\
18.5 \\
12.5 \\
15 \\
10.5 \\
3.5\end{array}$ \\
\hline $\begin{array}{l}\text { Name of surgeries } \\
\text { Open reduction internal fixation } \\
\text { Open reduction external fixation } \\
\text { Total hip replacement } \\
\text { Total knee replacement } \\
\text { Bone graft } \\
\text { Debridement } \\
\text { Corrective osteotomy }\end{array}$ & $\begin{array}{c}77 \\
43 \\
35 \\
22 \\
10 \\
5 \\
8 \\
\end{array}$ & $\begin{array}{c}38.5 \\
21.5 \\
17.5 \\
11 \\
5 \\
2.5 \\
4 \\
\end{array}$ \\
\hline
\end{tabular}


Table (2): Distribution of the operating team practices of surgical safety measures applied to the intraoperative orthopedic patients during preoperative verification phase

\begin{tabular}{|c|c|c|c|c|c|}
\hline \multirow{3}{*}{\multicolumn{2}{|c|}{$\begin{array}{l}\text { Preoperative verification } \\
\text { (Phase I) }\end{array}$}} & \multicolumn{4}{|c|}{ Intra-operative patient $(\mathrm{N}=200)$} \\
\hline & & \multicolumn{2}{|c|}{ Yes } & \multicolumn{2}{|c|}{ No } \\
\hline & & $\mathbf{N}$ & $\%$ & $\mathbf{N}$ & $\%$ \\
\hline 1 & Verify correct operation and site on the schedule & 200 & 100 & 0 & 0 \\
\hline 2 & $\begin{array}{l}\text { Verify correct operation site, history and physical } \\
\text { record }\end{array}$ & 200 & 100 & 0 & 0 \\
\hline 3 & Verify correct operation and site on the consent & 183 & 91.5 & 17 & 8.5 \\
\hline 4 & $\begin{array}{l}\text { Verify all the following relevant information is } \\
\text { available: } \\
\text { History } \\
\text { Consent } \\
\text { Diagnostic test results } \\
\text { Images }\end{array}$ & $\begin{array}{l}200 \\
183 \\
200 \\
197\end{array}$ & $\begin{array}{r}100 \\
91.5 \\
100 \\
98.5\end{array}$ & $\begin{array}{c}0 \\
17 \\
0 \\
3\end{array}$ & $\begin{array}{c}0 \\
8.5 \\
0 \\
1.5\end{array}$ \\
\hline 5 & Confirm site marked & 183 & 91.5 & 17 & 8.5 \\
\hline 6 & $\begin{array}{l}\text { Verify patient's identity, understanding and } \\
\text { agreement with all other relevant information }\end{array}$ & 191 & 95.5 & 9 & 4.5 \\
\hline 7 & $\begin{array}{l}\text { Confirm that all the following are available: } \\
\text { Required blood products } \\
\text { Implant devices } \\
\text { Special equipment }\end{array}$ & $\begin{array}{l}121 \\
142 \\
141 \\
\end{array}$ & $\begin{array}{l}60 \\
71 \\
70 \\
\end{array}$ & $\begin{array}{l}79 \\
58 \\
59 \\
\end{array}$ & $\begin{array}{c}39.5 \\
29 \\
29.5 \\
\end{array}$ \\
\hline 8 & $\begin{array}{l}\text { Verify that all sterile equipment and supplies are } \\
\text { prepared }\end{array}$ & 190 & 95 & 10 & 5 \\
\hline
\end{tabular}

Table (3): Distribution of the operating team practices of surgical safety measures applied to the intraoperative orthopedic patients during sign in phase

\begin{tabular}{|c|c|c|c|c|c|}
\hline \multirow{3}{*}{\multicolumn{2}{|c|}{$\begin{array}{l}\text { Sign in } \\
\text { (Phase II: before induction of anesthesia) }\end{array}$}} & \multicolumn{4}{|c|}{ Intra-operative patients $(\mathrm{N}=\mathbf{2 0 0})$} \\
\hline & & \multicolumn{2}{|c|}{ Yes } & \multicolumn{2}{|c|}{ No } \\
\hline & & $\mathbf{N}$ & $\%$ & $\mathbf{N}$ & $\%$ \\
\hline 1 & Complete check of anesthesia machine & 199 & 99.5 & 1 & 0.5 \\
\hline 2 & Complete check if medications & 200 & 100 & 0 & 0 \\
\hline 3 & $\begin{array}{l}\text { Verify that the pulse oximeter is present and } \\
\text { functioning }\end{array}$ & 187 & 93.5 & 13 & 6.5 \\
\hline 4 & Confirm any known patient allergies & 138 & 69 & 62 & 31 \\
\hline 5 & $\begin{array}{l}\text { Assess patient for risk of difficult airway and } \\
\text { aspiration }\end{array}$ & 114 & 57 & 86 & 43 \\
\hline 6 & Assess patient for risk of $>500 \mathrm{ml}$ blood loss & 124 & 62 & 76 & 38 \\
\hline 7 & Assess if intravenous access and fluid are planned & 193 & 95.5 & 7 & 3.5 \\
\hline
\end{tabular}


Table (4): Distribution of the operating team practices of surgical safety measures applied to the intraoperative orthopedic patients during time out phase

\begin{tabular}{|c|c|c|c|c|c|c|}
\hline \multirow{3}{*}{$\begin{array}{l}\text { Time out } \\
\text { (Phase III: after induction of anesthesia, } \\
\text { before the skin incision) }\end{array}$} & \multicolumn{6}{|c|}{ Intra-operative patients $(\mathrm{N}=\mathbf{2 0 0})$} \\
\hline & \multicolumn{2}{|c|}{ Yes } & \multicolumn{2}{|c|}{ No } & \multicolumn{2}{|c|}{$\begin{array}{l}\text { Not } \\
\text { applicable }\end{array}$} \\
\hline & $\mathbf{N}$ & $\%$ & $\mathbf{N}$ & $\%$ & $\mathbf{N}$ & $\%$ \\
\hline $\begin{array}{l}\text { Introduce all team members to each other } \\
\text { (Identify themselves to one another by name and } \\
\text { specify their functions during this procedure) }\end{array}$ & 5 & 2.5 & 195 & 97.5 & 0 & 0 \\
\hline \multicolumn{7}{|l|}{ Operating team verbally confirm: } \\
\hline a) The patient's name & 138 & 69 & 62 & 31 & 0 & 0 \\
\hline b) The planned procedure, site and position & 199 & 99.5 & 1 & 0.5 & 0 & 0 \\
\hline $\begin{array}{l}\text { c) If antibiotic prophylaxis was given to the } \\
\text { patient within } 60 \text { minutes before the } \\
\text { incision }\end{array}$ & 194 & 97 & 6 & 3 & 0 & 0 \\
\hline $\begin{array}{l}\text { d) If venous thrombolism prophylaxis (VTE) } \\
\text { has been undertaken }(\mathrm{N}=15)\end{array}$ & 15 & 7.5 & 0 & 0 & 185 & 92.5 \\
\hline \multicolumn{7}{|l|}{ Operating team verbally discuss: } \\
\hline a) Anticipated blood loss & 187 & 93.5 & 13 & 6.5 & 0 & 0 \\
\hline b) How long the case should take & 200 & 100 & 0 & 0 & 0 & 0 \\
\hline c) Any specific equipment & 139 & 69.5 & 61 & 30.5 & 0 & 0 \\
\hline d) Any patient-specific concerns & 118 & 59 & 82 & 41 & 0 & 0 \\
\hline e) Required monitoring equipment & 200 & 100 & 0 & 0 & 0 & 0 \\
\hline \multicolumn{7}{|l|}{ Operating teamverbally confirm: } \\
\hline $\begin{array}{l}\text { a) The sterility of all sterile equipment and } \\
\text { supplies }\end{array}$ & 200 & 100 & 0 & 0 & 0 & 0 \\
\hline $\begin{array}{l}\text { b) If there are any equipment issues or } \\
\text { concerns }\end{array}$ & 130 & 65 & 70 & 35 & 0 & 0 \\
\hline
\end{tabular}


Table (5): Distribution of the operating team practices of surgical safety measures applied to the intraoperative orthopedic patients during sign out phase

\begin{tabular}{|c|c|c|c|c|c|c|}
\hline \multirow{3}{*}{$\begin{array}{l}\text { Sign out } \\
\text { (Phase IV: at the completion of the } \\
\text { procedure but before wound closure is } \\
\text { completed) }\end{array}$} & \multicolumn{6}{|c|}{ Intra-operative patients $(\mathbf{N}=\mathbf{2 0 0})$} \\
\hline & \multicolumn{2}{|c|}{ Yes } & \multicolumn{2}{|c|}{ No } & \multicolumn{2}{|c|}{ Not applicable } \\
\hline & $\mathbf{N}$ & $\%$ & $\mathbf{N}$ & $\%$ & $\mathbf{N}$ & $\%$ \\
\hline $\begin{array}{l}\text { The OR team verbally confirms: } \\
\text { a) The name of procedure has been } \\
\text { recorded }\end{array}$ & 200 & 100 & 0 & 0 & 0 & 0 \\
\hline $\begin{array}{l}\text { b) Completion of instrument, sponge, } \\
\text { needle counts }\end{array}$ & 198 & 99 & 2 & 1 & 0 & 0 \\
\hline $\begin{array}{l}\text { c) Specimen labeling (read specimen } \\
\text { labels aloud, including patient } \\
\text { name })(\mathrm{N}=14) \text {. }\end{array}$ & 7 & 3.5 & 7 & 3.5 & 186 & 93 \\
\hline $\begin{array}{l}\text { d) Whether there are any equipment } \\
\text { problems to be addressed }(\mathrm{N}=35)\end{array}$ & 35 & 17.5 & 0 & 0 & 165 & 82.5 \\
\hline $\begin{array}{l}\text { Operating team review the key concerns } \\
\text { for recovery and management of the } \\
\text { patient }\end{array}$ & 124 & 62 & 76 & 38 & 0 & 0 \\
\hline
\end{tabular}

Table (6): Mean and standard deviations of four parts of Surgical Safety practices

\begin{tabular}{||l|c|c||}
\hline Surgical Safety practices & Mean & SD \\
\hline Part I :Preoperative verification phase & 89.75 & 10.32 \\
\hline Part II: Sign in phase & 76.06 & 14.82 \\
\hline Part III: Time out phase & 77.83 & 13.19 \\
\hline Part IV : Sign out phase & 86.48 & 16.11 \\
\hline
\end{tabular}


Table (7): Comparison between types of surgeries and 4 parts of Surgical Safety practices

\begin{tabular}{|c|c|c|c|c|c|c|c|c|}
\hline \multirow{3}{*}{ Surgery types } & \multicolumn{8}{|c|}{ Parts of Surgical Safety practices } \\
\hline & \multicolumn{2}{|c|}{$\begin{array}{c}\text { Part I } \\
\text { Preoperative } \\
\text { verification } \\
\text { phase }\end{array}$} & \multicolumn{2}{|c|}{$\begin{array}{c}\text { Part II } \\
\text { (Sign in phase) } \\
\text { Before } \\
\text { induction of } \\
\text { anesthesia }\end{array}$} & \multicolumn{2}{|c|}{$\begin{array}{c}\text { Part III } \\
\text { (Time out } \\
\text { phase) Before } \\
\text { skin incision }\end{array}$} & \multicolumn{2}{|c|}{$\begin{array}{c}\text { Part IV } \\
\text { (Sign out } \\
\text { phase) Before } \\
\text { patient leaves } \\
\text { OR }\end{array}$} \\
\hline & Mean & SD & Mean & SD & Mean & SD & Mean & SD \\
\hline $\begin{array}{l}\text { Open reduction } \\
\text { internal fixation }\end{array}$ & 89.286 & 9.65 & 73.026 & 13.166 & 78.090 & 13.85 & 82.675 & 17.043 \\
\hline $\begin{array}{l}\text { Open reduction } \\
\text { external fixation }\end{array}$ & 77.14 & 3.194 & 52.500 & 10.46 & 67.27 & 12.197 & 80.00 & 18.26 \\
\hline $\begin{array}{l}\text { Total hip } \\
\text { replacement }\end{array}$ & 95.24 & 7.475 & 84.167 & 12.909 & 82.47 & 9.439 & 92.77 & 12.55 \\
\hline $\begin{array}{l}\text { Total knee } \\
\text { replacement }\end{array}$ & 100.00 & 0.000 & 91.66 & 7.216 & 82.828 & 0.8748 & 100.00 & 0.000 \\
\hline Bone graft & 85.714 & 12.598 & 81.250 & 12.147 & 73.86 & 14.503 & 91.333 & 14.418 \\
\hline Debridement & 85.714 & 8.748 & 67.500 & 24.367 & 69.394 & 12.60 & 73.33 & 14.907 \\
\hline $\begin{array}{l}\text { Corrective } \\
\text { osteotomy }\end{array}$ & 85.714 & 13.766 & 68.75 & 9.449 & 72.06 & 11.634 & 81.25 & 15.905 \\
\hline $\begin{array}{l}\text { Chi-Square } \\
\text { Sig }\end{array}$ & \multicolumn{2}{|c|}{$\begin{array}{l}28.360 \\
.003 *\end{array}$} & \multicolumn{2}{|c|}{$\begin{array}{l}30.582 \\
.001 *\end{array}$} & \multicolumn{2}{|c|}{$\begin{array}{c}14.750 \\
.194\end{array}$} & \multicolumn{2}{|c|}{$\begin{array}{c}18.152 \\
.078\end{array}$} \\
\hline
\end{tabular}

Kruskal Wallis Test 
Table (8): Comparison between patients' age and four parts of Surgical Safety practices

\begin{tabular}{|c|c|c|c|c|c|c|c|c|}
\hline \multirow{3}{*}{$\begin{array}{l}\text { Patient } \\
\text { age }\end{array}$} & \multicolumn{8}{|c|}{ Parts of Surgical Safety practices } \\
\hline & \multicolumn{2}{|c|}{$\begin{array}{c}\text { Part I } \\
\text { Preoperative } \\
\text { verification phase }\end{array}$} & \multicolumn{2}{|c|}{$\begin{array}{c}\text { Part II } \\
\text { (Sign in phase) } \\
\text { Before induction } \\
\text { of anesthesia }\end{array}$} & \multicolumn{2}{|c|}{$\begin{array}{c}\text { Part III } \\
\text { (Time out phase) } \\
\text { Before skin } \\
\text { incision }\end{array}$} & \multicolumn{2}{|c|}{$\begin{array}{c}\text { Part IV } \\
\text { (Sign out phase) } \\
\text { Before patient } \\
\text { leaves OR }\end{array}$} \\
\hline & Mean & SD & Mean & SD & Mean & SD & Mean & SD \\
\hline $20-\leq 30$ & 86.429 & 11.414 & 70.93 & 14.262 & 76.458 & 12.49 & 84.167 & 16.211 \\
\hline $30-\leq 40$ & 87.45 & 8.973 & 69.93 & 15.155 & 74.75 & 15.016 & 82.207 & 16.68 \\
\hline $40-\leq 50$ & 89.14 & 9.914 & 72.000 & 13.635 & 76.36 & 12.309 & 81.66 & 16.666 \\
\hline $50-\leq 60$ & 90.000 & 11.5022 & 78.75 & 16.786 & 79.62 & 14.15 & 91.94 & 13.75 \\
\hline $60-\leq 70$ & 94.55 & 9.287 & 83.33 & 12.076 & 83.405 & 9.197 & 94.048 & 12.677 \\
\hline $70-\leq 80$ & 96.939 & 8.099 & 82.14 & 9.834 & 88.42 & 6.925 & 92.857 & 18.89 \\
\hline $\begin{array}{l}\text { Chi- } \\
\text { Square } \\
\text { Sig }\end{array}$ & \multicolumn{2}{|c|}{$\begin{array}{c}18.566 \\
.005^{*}\end{array}$} & \multicolumn{2}{|c|}{$\begin{array}{c}20.266 \\
.002 *\end{array}$} & \multicolumn{2}{|c|}{$\begin{array}{c}14.306 \\
.026 *\end{array}$} & \multicolumn{2}{|c|}{$\begin{array}{c}17.535 \\
.008 *\end{array}$} \\
\hline
\end{tabular}

Kruskal Wallis Test 


\section{References}

1. Sukhmeet SP, Douglas JN, Saqeb BM, Bhavesh P, Bhupinder M, Emerton M. Can the surgical checklist reduce the risk of wrong site surgery in orthopaedics? - can the checklist help? Supporting evidence from analysis of a national patient incident reporting system. Journal of Orthopedic Surgery and Research 2011; 6(18):1-7.

2. Makary MA, Sexton JB, Freischlag JA, Millman EA, Pryor D, Holzmueller C, Pronovost PJ. Patient Safety in Surgery. Annals of Surgery 2006; 243(5):628635.

3. De Vries EN, Ramrattan MA, Smorenburg SM, Gouma DJ, Boermeester MA. The incidence and nature of in-hospital adverse events: a systematic review. Quality Safety Health Care 2008; 17(3):216-223.

4. Jarrett MP. Patient Safety and Leadership:Do You Walk the Walk? Journal of Healthcare Management 2017 ;62 (2):88-92.

5. World alliance for patient safety. Implementation manual surgical safety checklist (first edition) Safe Surgery Saves Lives. World Health Organization 2008. Available at: http://www.who.int/patientsafety/challe nge/safe.surgery/en/.

6. Constanza CA, Liliana B, Alvaro Q , León E Q, Marcela MD. Checklist verification for surgery safety from the patient's perspective. Colombian Journal of anestesiology. 2013; 41(2):109-113.

7. Attitudes towards the Surgical Safety Checklist and its Use in New Zealand Operating Theatres. Prepared for the Health Quality and Safety Commission New Zealand, 19 October 2012.

8. Elsous A, Akbarisari A, Rashidian A, Aljeesh Y, Radwan M.and Abu Zaydeh H. Psychometric Properties of an
Arabic Safety Attitude Questionnaire .Oman Medical Journal 2017;32,(2): 115-123.

9. Khater WA, Akhu-zaheya LM, ALMahasneh.SI, Khater R. Nurses' perceptions of patient safety culture in Jordanian hospitals. International Nursing Review.2015; 62(1):82-91.

10. Cheever KH, Hinkee JL. Brunner \& Suddarth's Textbook of MedicalSurgical Nursing. Intraoperative Nursing Management. 13th Edition. Lippincott William \& Wilkins, 2014; 419-420.

11. Vincent C, Moorthy K, Sarker SK, Chang A, Darzi AR. Systems approaches to surgical quality and safety. Ann Surg. Apr 2004; 239(4): 475-482.

12. Olsen S, Undre S, Vincent C. Safety in surgery: First steps towards a systems approach. Clinical Risk 2005; 11: 190 194.

13. Pennsylvania patient safety advisory. Produced by Emergency Care Research Institute (ECRI) and The Institute for Safe Medication Practices (ISMP) under contract to the Pennsylvania. Patient Safety Authority, June 2011.

14. Carayon P, Madison GB, Kenneth EW. Patient Safety: The Role of Human Factors and Systems Engineering. Studies in Health Technology and Informatics. 2010; 153: 23-46.

15. Fardin Mehrabian, Said Asefzade, Shila Kianmehr. Relationship between patient safety and nurse's teamwork in ICU, CCU and operating rooms in health centers of Rasht in 2013. J Biol. Today's World.2015 Jan; 4(1):6-12

16. Charles Vincent, Krishna Moorthy, Sudip K. Sarker, Avril Chang, Ara W. Darzi. Systems Approaches to Surgical Quality and Safety From Concept to 
Measurement. Annals of Surgery. 2004 April; 239(4): 475-482.

17. Robinson PM, Muir LT. Wrong-site surgery in orthopaedics. The Journal of Bone and Joint Surgery.2009; 91-b: 1274-80.

18. Philip SP, Philip Ms, Clarke TJ, Varnell J.The $5^{\text {th }}$ anniversary of the "Universal Protocol": pitfalls and pearls revisited. Patient Safety in Surgery 2009; 3(14): 1-9.

19. American Academy of Orthopaedic Surgeons. Report of the task force on wrong-site surgery. Available at: http://www.aaos.org/wordhtml /meded/tasksite.htm. [Accessed July 18, 2005].

20. Committee on patient safety and quality improvement. Patient safety in the surgical environment. Committee Opinion, 2010 September, 464:1-5.

21. Frederique ES, Kjeld HA. Patient safety in the operating theatre: how A3 thinking can help reduce door movement. Int $\mathbf{J}$ Qual Health Care (2014) published online: April 3, 2014.

22. Geraldo F. et al. The WHO Surgical Safety Checklist: knowledge and use by Brazilian orthopedists. Revista Brasileria de Ortopedia .2013; 48(6): 554-562.

23. Nissen SO, Bukhari N, Dragsted C,Gehrchen M, Johansson PI. Blood transfusion in the surgical treatment of adolescent idiopathic scoliosis-a single-center experience of patient blood management in 210 cases. Transfusion 2017, 8 (4): 1-10.

24. Rydenfält C, johansson1 G, Odenrick P, Akerman K Larsson PA. Compliance with the WHO Surgical Safety Checklist: deviations and possible improvements. International Journal for Quality in Health Care 2013; 25, (2): 182-187
25. Ragusa PS, Bitterman A, Auerbach B, Healy WA. Effectiveness of Surgical Safety Checklists in Improving Patient Safety.Orthopedic 2016 March: 1-4.

26. Gans I, Jain A, Norachart S, Elliott RH, Hasenboehler EA. Current practice of antibiotic prophylaxis for surgical fixation of closed long bonefractures: a survey of 297 members of the Orthopaedic Trauma Association. Patient Safety in Surgery 2017; 11(2): 1-6.

27. Labrague LJ, Arteche DL, Yboa BC, Pacolor NF. Operating Room Nurses' Knowledge and Practice of Sterile Technique. Nursing \& Care 2012; 1(4).

28. Eefje N. de Vries et al. Effect of a Comprehensive Surgical Safety System on Patient Outcomes. The New England and Journal of Medicine. 2010; 363:1928-1937.

29. Lingard L. et al. Communication failures in the operating room: an observational classification of recurrent types and effects. Quality \& Safety Health Care 2004; 13: 330-334.

30. Melekie1 TB, Getahun GM. Compliance with Surgical Safety Checklist completion in the operating room of University of Gondar Hospital, Northwest Ethiopia. Bio Med Central, 2015, 8:361-367.

31. Griffiths R. Peri-operative care of the elderly. Anaesthesia January 2014, 69, (S1):81-98. 